\title{
Abordagem da ergonomia e da acessibilidade para desenvolvimento de uma cartilha voltada para projetos comerciais para o público idoso
}

\author{
Ergonomics and accessibility approach for the development of a \\ booklet for commercial projects for the elderly public
}

\author{
ANA BEATRIZ CORDEIRO DE OLIVEIRA BELMIRO \\ Especialista em Arquitetura Comercial e Corporativa, Centro Universitário de João \\ Pessoa/Unipê, beatrizc.designer@gmail.com \\ JÚLIO CÉSAR FELIX DE ALENCAR FERNANDES \\ Doutorando em Design, Universidade de Aveiro, Portugal, julio.interiores85@gmail.com \\ LARISSA NASCIMENTO DOS SANTOS \\ Doutoranda em Design, UFPE, larissansns@gmail.com
}

\section{RESUMO}

O presente trabalho trata sobre a abordagem dos conceitos da acessibilidade e da ergonomia nos projetos de interiores comerciais voltados para o público da terceira idade. Partindo-se da premissa de que os idosos têm necessidades específicas, em virtude de limitações advindas da mobilidade reduzida e possíveis doenças próprias da idade, este trabalho baseou-se na intenção de compilar diretrizes, encontradas em normas e estudos, adaptando-as para este perfil de usuário. Para tanto, foi realizada uma pesquisa bibliográfica contemplando todos os aspectos voltados ao projeto de interiores, visando a acessibilidade e a ergonomia em referências atualizadas. As recomendações foram extraídas de Normas Técnicas da ABNT, como a NBR 9050 (2015), a NR 17 (2007), a NBR ISO/CIE8995-1 (2013) e a NBR 5413 (1992). Além disso, foram considerados estudos em andamento com o mesmo objetivo, onde todos os dados foram sintetizados a fim de gerar uma tabela a ser consultada para futuros projetos que promovam o acesso independente, seguro e confortável de pessoas idosas em estabelecimentos comerciais.

PALAVRAS-CHAVE: Idoso; acessibilidade; ergonomia; projetos comerciais

\section{ABSTRACT}

This work deals with the approach to the concepts of accessibility and ergonomics in commercial interior projects for the elderly public. Starting from the premise that the elderly have specific needs, due to limitations arising from reduced mobility and possible age-related diseases, this work was 


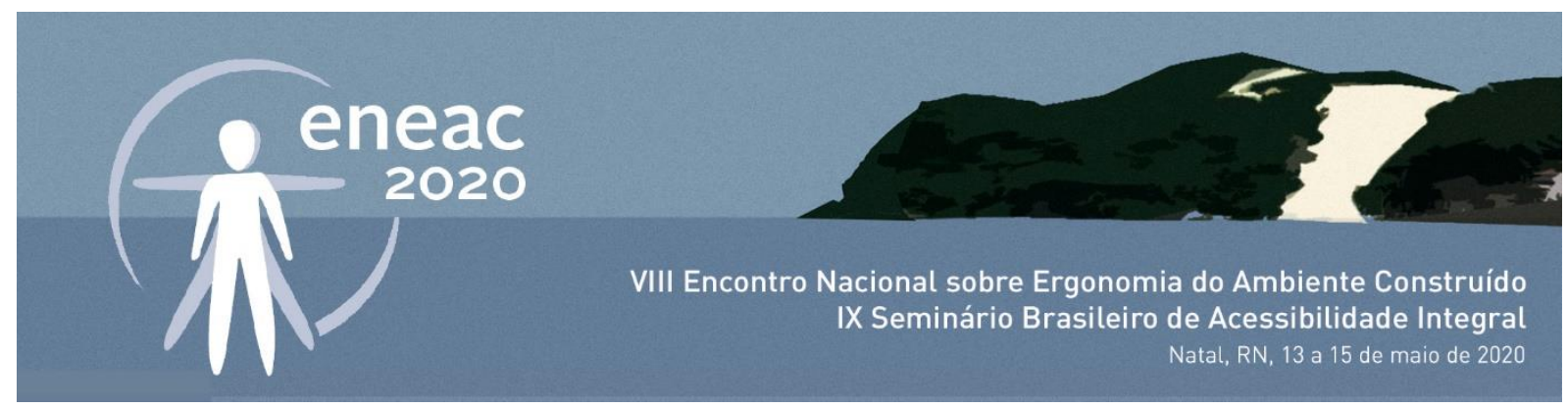

based on the intention of compiling guidelines, found in standards and studies, adapting them to this user profile. For this, a bibliographical research was carried out contemplating all the aspects directed to the project of interiors, aiming at the accessibility and the ergonomics in updated references. The recommendations were extracted from ABNT Technical Standards, such as NBR 9050 (2015), NR 17 (2007), NBR ISO/CIE8995-1 (2013) and NBR 5413 (1992). In addition, ongoing studies were considered with the same objective, where all data were synthesized in order to generate a table to be consulted for future projects that promote independent, safe and comfortable access for elderly people in commercial establishments.

KEYWORDS: Elderly; old man; accessibility; ergonomics; commercial projects

\section{INTRODUÇÃO}

Esta proposta de estudo a nível teórico tem como tema investigar os parâmetros e diretrizes a serem contemplados na elaboração de um projeto voltado para o público idoso. Em João Pessoa, a população, segundo o último censo realizado pelo IBGE em 2010, é estimada em mais de 720 mil habitantes, tendo uma parcela de 74 mil composta por pessoas acima de 60 anos.

Tabela 1 - Número de idosos em João Pessoa e na Paraíba (ano 2000)

\begin{tabular}{|c|c|c|c|}
\hline & Homens & Mulheres & Total \\
\hline Paraíba & 155.840 & 194.726 & 350.566 \\
\hline João Pessoa & 18.817 & 29.855 & 48.672 \\
\hline
\end{tabular}

Tabela 2 - Número de idosos em João Pessoa e na Paraíba (ano 2010)

\begin{tabular}{|c|c|c|c|}
\hline & Homens & Mulheres & Total \\
\hline Paraíba & 195.451 & 255.934 & 451.385 \\
\hline João Pessoa & 29.002 & 45.633 & 74.635 \\
\hline
\end{tabular}

Pode-se perceber, com os índices populacionais do IBGE das tabelas acima, o nível de crescimento da população idosa, e assim, vislumbrar que o potencial de envelhecimento continuará em significativa evolução.

As pessoas acima de 60 anos têm necessidades específicas por limitações naturais, as quais ocorrem devido ao desgaste físico do corpo ao longo dos anos. Quando se fala em saúde não há uma régua exata que diz quais limitações ou doenças o idoso terá, porém muitos estudos mostram as mais 


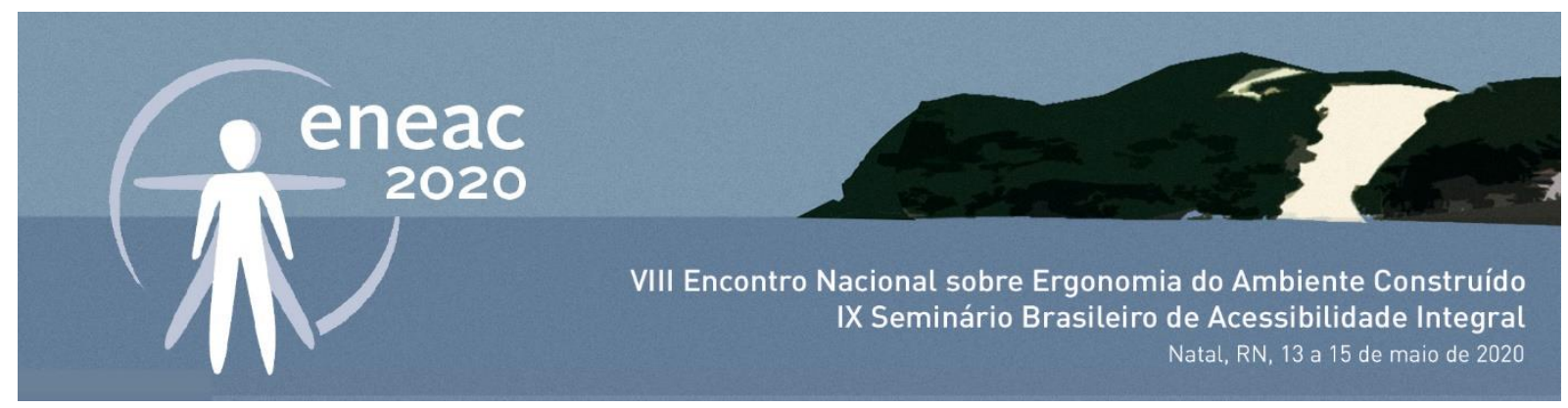

recorrentes e seus possíveis tratamentos ou prevenções. A nível de projeto, para este perfil de usuários, deverão ser tomados parâmetros próprios e cuidados extras em comparação com o público geral. Por estes motivos é relevante estudar os aspectos que envolvem este público, a fim de sanar ou diminuir os efeitos das possíveis deficiências do idoso numa loja de vestuário.

No século XX a expectativa de vida, no Brasil, era menor que os 40 anos, este fator freava o crescimento da população, segundo CHAIMOWICZ (2009), o autor continua mostrando que com o avanço do desenvolvimento e uso de medicamentos e melhoria na atenção básica da saúde da população, na década de 70 a expectativa era de 54 anos e 65 anos em 2005. Estimando que, com isso, o Brasil poderá passar do 16ㅇ lugar para o 70 lugar no ranking dos países com as expectativas de vida mais altas.

O objetivo central deste estudo é pontuar parâmetros e diretrizes a serem consideradas em projetos comerciais voltados para o público idoso. Para isso, considerou-se também o estudo sobre as normas de ergonomia voltadas para este público, a identificação das doenças do idoso e suas possíveis influências no projeto e dos materiais e recursos adequados para o uso seguro do idoso.

Sempre que se pretende analisar quais as abordagens corretas ao se projetar, deve-se estudar a ergonomia. As influências do campo da ação da ergonomia são amplas, pode-se observar de vários pontos de partida, desde as dimensões antropométricas, até a forma de concepção de produtos industriais e de projetos arquitetônicos, com isto, a ergonomia contribui para a elaboração de soluções, métodos e técnicas, participando na concepção do projeto, segundo FALZON (2018).

\section{REFERENCIAL TEÓRICO}

De acordo com o Estatuto do Idoso (BRASIL, 2013), a população vem envelhecendo de maneira progressiva, aumentando os percentuais de cidadãos com mais de 60 anos. $O$ Estatuto estima que, no ano de 2025, o número destes alcançará 32 milhões, tornando o Brasil o sexto país com mais idosos no mundo, e em 2050 este número pode ser igual ou maior que a faixa etária de até 15 anos. Este envelhecimento da população dar-se, também, de maneira saudável. Boa parte dos idosos conservam suas capacidades físicas e consegue realizar as atividades rotineiras e contribuir para a vida em família e na sociedade.

A Organização Mundial da Saúde orienta que as organizações internacionais devem fomentar políticas públicas para favorecer o "envelhecimento ativo", objetivando a melhoria na qualidade de vida do idoso e sua inserção na sociedade (BRASIL, 2005).

Na Lei no13.146 (BRASIL, 2015), o Estatuto da Pessoa com Deficiência - documento que representa uma divisão histórica e jurídica na proteção dos direitos das pessoas com deficiência - encontram-se as seguintes definições:

"Art. 2 Considera-se pessoa com deficiência aquela que tem impedimento de longo prazo de natureza física, mental, intelectual ou sensorial, o qual, em interação com uma ou mais barreiras, pode obstruir sua participação plena e efetiva na sociedade em igualdade de condições com as demais pessoas." 


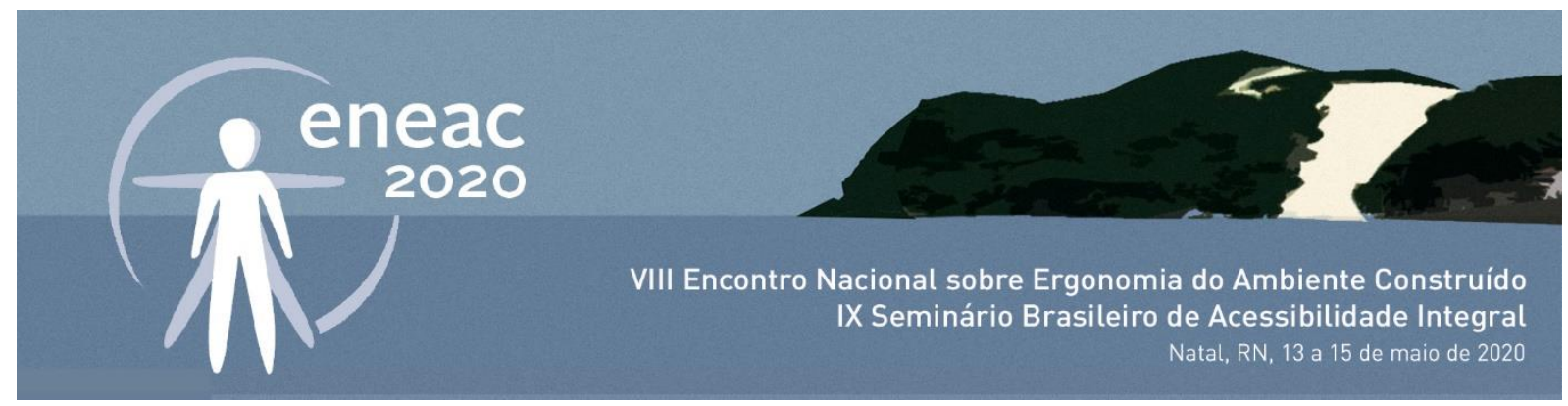

"Art. 3, inciso IV - barreiras: qualquer entrave, obstáculo, atitude ou comportamento que limite ou impeça a participação social da pessoa, bem como o gozo, a fruição e o exercício de seus direitos à acessibilidade, à liberdade de movimento e de expressão, à comunicação, ao acesso à informação, à compreensão, à circulação com segurança, entre outros, classificadas em:

a) barreiras urbanísticas: as existentes nas vias e nos espaços públicos e privados abertos ao público ou de uso coletivo;

b) barreiras arquitetônicas: as existentes nos edifícios públicos e privados;

c) barreiras nos transportes: as existentes nos sistemas e meios de transportes;

d) barreiras nas comunicações e na informação: qualquer entrave, obstáculo, atitude ou comportamento que dificulte ou impossibilite a expressão ou o recebimento de mensagens e de informações por intermédio de sistemas de comunicação e de tecnologia da informação;

e) barreiras atitudinais: atitudes ou comportamentos que impeçam ou prejudiquem a participação social da pessoa com deficiência em igualdade de condições e oportunidades com as demais pessoas;

f) barreiras tecnológicas: as que dificultam ou impedem o acesso da pessoa com deficiência às tecnologias;"

Com estes dispositivos, pode-se perceber que a noção de deficiência esta intrinsicamente ligada à existência de barreiras. Ou seja, trabalhar previamente para eliminação de tais obstáculos é, também, eliminar ou diminuir os efeitos destas barreiras.

Algumas doenças e limitações próprias da idade afetam a qualidade de vida deste público, como por exemplo: a osteoartrose - causa a limitação dos movimentos, principalmente nos joelhos osteoporose, a qual aumenta o risco de fraturas ósseas, raciocínio mais lento, demências, depressão, entre outras CHAIMOWICZ (2009).

Outros impactos na vida do idoso, advindos destas limitações, podem ser: a redução da força motora e da destreza articular; diminuição do equilíbrio corporal, o que causa a incidência de quedas; perda parcial da capacidade visual e da audição, podendo afetar, também, os outros sentidos e lentidão no entendimento das informações e maior tempo para tomada de decisões. (LAVILLE; VOLKOFF, 2007)

Deve-se ponderar os reflexos e consequências que este cenário, com um perfil mais idoso, pode causar na sociedade. Como por exemplo: nos atendimentos e logísticas dos serviços de saúde, atendimento em órgãos públicos, empresas privadas, no setor de entretenimento, nos ambientes de trabalho, entre outros. Pois, os idosos têm características peculiares a idade, de forma a interferir diretamente nos ambientes onde interagem.

Desta forma, pensar em projetar para este público requer conhecimentos prévios dessas características, as quais nortearão e modificarão as tomadas de decisões no ambiente projetado. Para FERNANDES (2012), algumas dessas são as limitações naturais intrínsecas ao envelhecimento, as quais podem trazer danos ao sistema neurológico e musculoesquelético e comprometer a acuidade visual, força e a locomoção. 




Todos os profissionais envolvidos nos projetos de ambiente construído devem considerar sempre o risco de quedas dos idosos, além de observar as características funcionais, biomecânicas e antropométricas da população usuária, pois assim contribuirão para a melhoria da qualidade de vida dessas pessoas (REIS; MERINO, s/d)

O projeto de interiores comercial voltado para este público, deverá diminuir essas problemáticas e facilitar a visualização, o acesso e a prova dos produtos. Através do respeito às normas regulamentadores condizentes com o caso e diretrizes, cujo objetivo é facultar, dar prazer e incentivar a processo de compra das peças.

Deve-se considerar a NBR 9050 (ABNT, 2015), cujos padrões de acessibilidade servirão como balizadores para definição de pontos, como: espaçamentos e circulações adequados, dimensionamento do mobiliário, materiais e dispositivos de segurança e apoio (corrimões e barras), rampas e acessos, dentre outros parâmetros.

Para o público em geral há certa dificuldade em escolher suas roupas e vestir-se (numa loja de vestuário, por exemplo), no caso dos idosos esta dificuldade é aumentada, pois suas noções sensoriais, podendo estar afetadas, fazem esta tarefa ter maior grau de complexidade, devido aos botões, zíperes, elásticos, ganchos, etc. Pois estes aviamentos exigem movimentos motores finos (GRUBER; MERINO; MERINO, 2017).

A fim de proporcionar maior conforto e sucesso dessas atividades podem ser usadas as TAs (Tecnologias Assistivas), ferramentas e dispositivos que diminuam os efeitos das deficiências em decorrência da idade (COOK; POLGAR; HUSSEY, 2008).

\section{METODOLOGIA}

Esta pesquisa foi resultado de um trabalho apresentado ao Centro Universitário de João Pessoa, como parte das exigências para a obtenção do título de Especialista em Arquitetura Comercial e Projetos Corporativos.

Etapas para desenvolvimento do trabalho:

- Fase 01 - Pesquisa bibliográfica: Nesta fase, foi realizado o levantamento de dados acerca do objeto de estudo, mediante pesquisa em normas regulamentadores, artigos e livros de referência.

- Fase 02 - Levantamento de trabalhos/estudos correlatos: Pesquisas em estudos teóricos e projetos com o mesmo foco do presente trabalho.

- Fase 03 - Análise das informações: Após a coleta de todas as informações, os dados foram analisados, a fim de elaborar a fundamentação teórica para o artigo. 


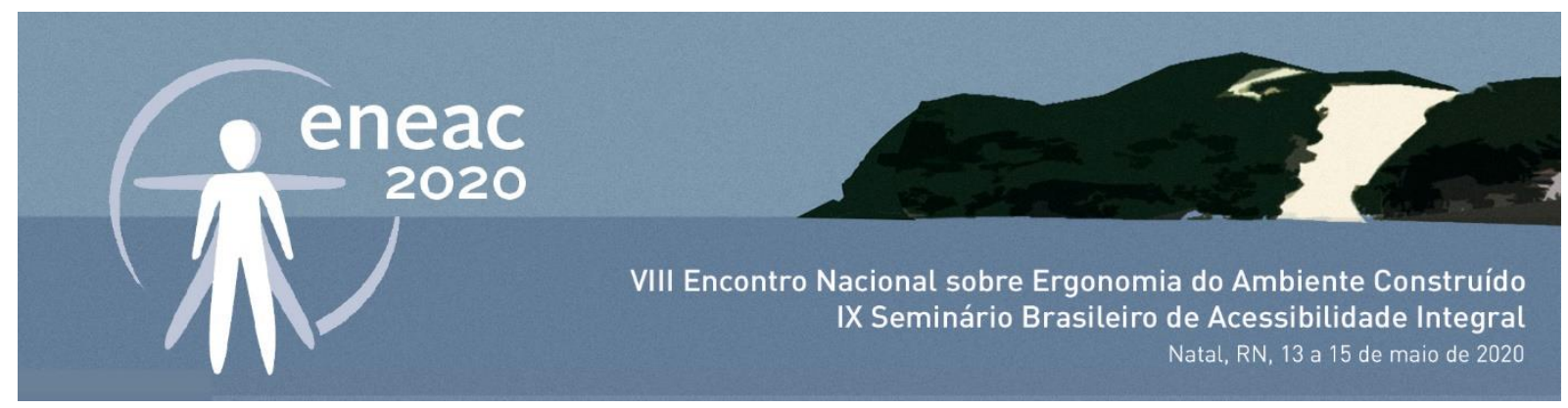

\section{RESULTADOS}

Os resultados deste trabalho foram compilados em forma de uma macro tabela para uma compreensão mais fluida e organizada, após a análise de pontos importantes - e de normas regulamentadoras - a serem ressaltados num projeto voltado para idosos. As recomendações foram extraídas de Normas Técnicas da ABNT, como a NBR 9050 (2015), a NR 17 (2007), a NBR ISO/CIE89951 (2013) e a NBR 5413 (1992).

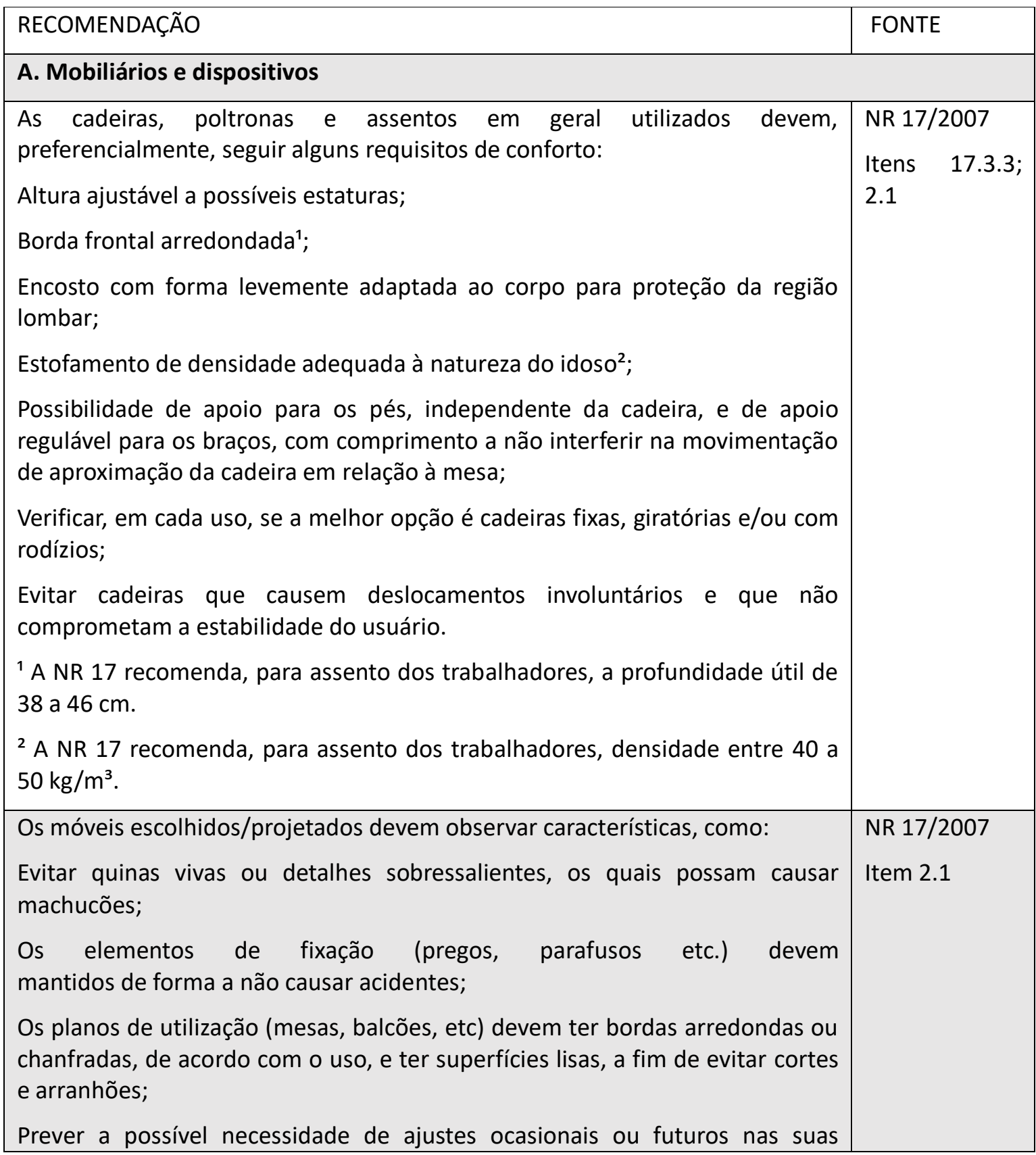


dimensões

Caso haja fones de ouvido (head-sets) para uso dos usuários, estes devem:

Ter garantidas a correta higienização e as condições operacionais recomendadas pelos fabricantes;

Ser substituído prontamente quando situações irregulares de funcionamento forem detectadas pelo operador;

Permitir ajuste individual da intensidade do nível sonoro e ser providos de sistema de proteção contra choques acústicos e ruídos indesejáveis de alta intensidade.

Em relação ao mobiliário e equipamentos, no seu uso de forma geral, as suas dimensões devem:

Assegurar uma postura confortável ao usuário na posição sentada e em pé, e dos membros superiores e inferiores;

NR $17 / 2007$

Itens 2.1;

$2.2 ; 2.3 ; 2.4$

Respeitar os ângulos limites e trajetórias naturais dos movimentos, durante a execução das tarefas, evitando a flexão e a torção do tronco;

Ser especificadas para favorecer os movimentos da função exercida, sem exigir força, flexão ou extensão acentuadas;

Estar dentro dos limites de alcance manual e visual do idoso, permitindo a movimentação natural dos membros superiores e inferiores;

Prevenir acidentes de natureza mecânica ou elétrica;

Prever, quando necessário, a possibilidade de adaptações.

\section{B. Organização de atividades}

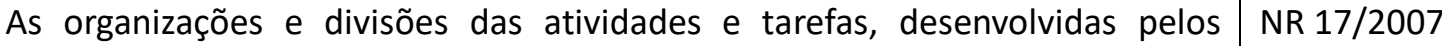
idosos, devem levar em consideração:

O modo de executar;

O tempo médio de execução;

Quais possíveis os movimentos e deslocamentos;

As amplitudes de alcance manual e visual.

\section{Análise postural e conforto físico-ambiental}

Analisar se as atividades a serem realizadas deverão ser realizadas em pé ou sentado, e com base nisso, especificar possíveis:

Apoios ajustáveis para os pés e braços;

Item 17.6.2

NR 17/2007

Itens 17.3.4;

17.3.5 


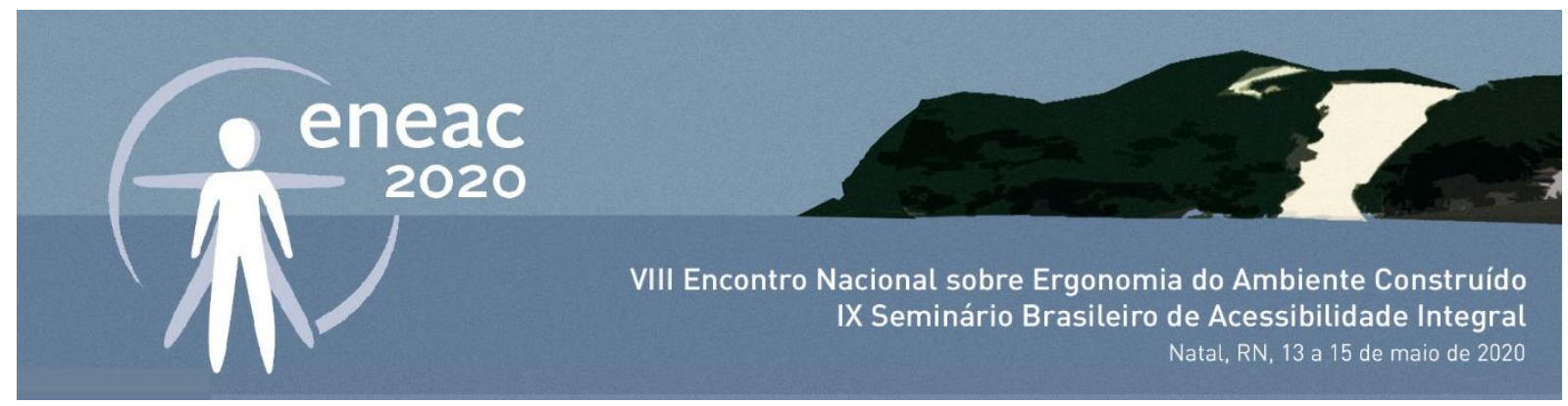

Barras de apoio;

Locais de descanso para pausas.

Nos ambientes de negociações, como mesas, balcões, postos de atendimento, entre outros, deve-se considerar o ato da leitura de documentos, contratos e afins, e oferecer apoio e iluminação adequados, proporcionando boa postura e visualização a fim de evitar movimentação frequente do pescoço e fadiga visual.

Para utilização de terminais de vídeo, observar:

NR $17 / 2007$

Mobilidade para permitir o ajuste da tela do equipamento à iluminação do ambiente, protegendo a visão do idoso contra reflexos;

O teclado deve ser independente e ter mobilidade;

Teclados, mouses e outros dispositivos, preferencialmente, devem ser posicionados em superfícies com altura ajustável.

Nos ambientes em geral devem ser consideradas as seguintes variáveis:

Níveis de ruído confortáveis;

Índices de temperatura e suas variações, de preferencia entre 20 ㅇ e $23 \circ C$;

Item 17.4.3

Umidade relativa do ar não inferior a $40 \%$.

Em todos os ambientes a iluminação deve ser adequada, podendo ser natural ou artificial, geral ou suplementar e adaptada a cada atividade específica. A iluminação geral deve ser uniformemente distribuída e difusa, projetada de maneira a evitar ofuscamento, sombreamento, reflexos incômodos e contrastes excessivos.

As instalações do ambiente devem proteger os usuários contra correntes de ar, vento ou grandes variações climáticas.

NR $17 / 2007$

Item17.5.2;

4.2

NR $17 / 2007$

Itens 17.5.3.;

17.5.3.1;

17.5.3.2.

NR $17 / 2007$

Item 2.3

Para o atendimento das pessoas idosas, gestantes, portadoras de deficiências ou que apresentem algum tipo de mobilidade reduzida, a empresa deve disponibilizar pessoal auxiliar e especializado.

Para evitar sobrecarga de informações, a nível psicológico, e físico, a nível corporal do idoso, as empresas devem prever possíveis pausas de descanso e intervalos na circulação da loja.

Para as pessoas com deficiência ou mobilidade reduzida, caso de muitos idosos, as decisões projetuais devem contemplar:

Adaptações para atender às suas necessidades;

NR $17 / 2007$

Item 3.5.

NR $17 / 2007$

Item 5.4.

NR $17 / 2007$

Itens 9; 9.1;

Ajudas técnicas necessárias, a fim de melhorar a interação do idoso com o meio, dando-Ihe mais autonomia;

A análise do acesso às instalações, ao mobiliário, aos equipamentos e as 


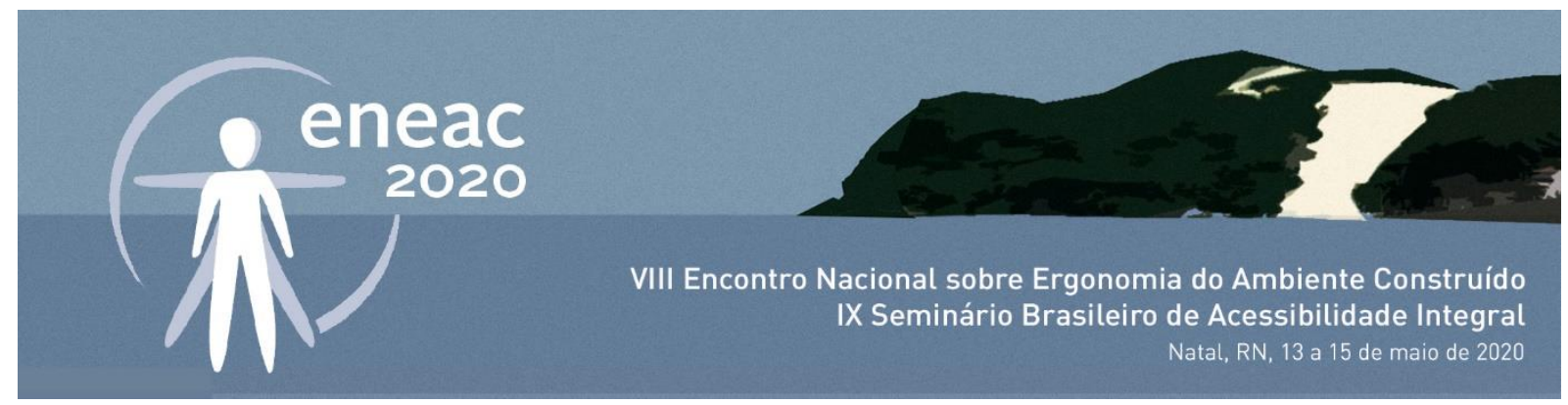

condições ambientais e sanitárias;

Atendimento especializado para o público alvo em questão.

\section{Materiais}

Os materiais dos documentos (contratos, recibos, panfletos, etc) devem ser de fácil legibilidade sempre que possível, evitando a utilização de papeis brilhante ou de outros tipos que causem ofuscamento.

Os materiais em geral, devem preferencialmente:

NR $17 / 2007$

Utilizar superfícies opacas ou que evitem reflexos incômodos no campo visual Item 2.1 dos usuários;

Ter material antiderrapante, quando necessário;

Ser estofadas e revestidas com material que permita a perspiração, quando forem superfícies com contato corporal

\section{E. Iluminação}

Uma boa iluminação além de favorecer adequada visualização da tarefa, $\mathrm{NBR}$ ISO/CIE também é primordial para o conforto e assegura aspectos como:

$8995-1 / 2013$

Sensação de bem-estar;

Item 4.1

Bom desempenho visual, ofertando ao idoso a autonomia de realizar as atividades dependentes da visão;

Segurança visual, ao se sentir apto para analisar o ambiente ao seu redor.

Para atender bons resultados lumínicos, deve-se considerar alguns parâmetros como:

Iluminância;

Ofuscamento;

Direção da luz;

Luz natural;

Aspectos das cores da luz e superfícies.

A distribuição correta da luminância está relacionada com o controle da adaptação dos olhos, este adequado balanceamento é importante para:

NBR ISO/CIE 8995-1/2013

A acuidade visual (nitidez da visão);

Item 4.2

A diferenciação de contrastes;

Melhor eficiência das funções oculares de acomodação, contrações pupilares, 
convergência, movimento dos olhos, entre outros.

O projeto lumínico, voltado para idosos, deve evitar:

Índices de iluminância altos que possam gerar ofuscamento;

Contrates na quantidade de luz distribuída no ambiente, pois isso pode causar fadiga visual pela continua readaptação dos olhos;

Alta variação da iluminação nos diferentes ambientes/setores do empreendimento.

Segundo a NBR ISO/CIE 8995-1 (ABNT, 2013) as principais superfícies internas mais importantes, em termos de iluminação e reflexão, são: o teto, paredes, planos de trabalho e o piso.

Entende-se como campo de trabalho, segundo a NBR 5413 (ABNT,1992), a área onde exigem-se condições de iluminância adequada para o trabalho visual a ser realizado. E por iluminância, o fluxo luminoso que incide na superfície em torno de um determinado ponto. Esta iluminância deve ser medida no campo de trabalho.

Entende-se por ofuscamento, de acordo com a definição da NBR ISO/CIE 8995-1 (ABNT, 2013), a sensação visual gerada por áreas brilhantes dentro de um campo de visão, podendo ser de dois tipos:

Ofuscamento desconfortável, que prejudica o senso de bem-estar. No interior dos ambientes, geralmente surge diretamente de luminárias ou janelas, se suas causas forem sanadas, o ofuscamento inabilitador, normalmente, não é um grande problema.

Ofuscamento inabilitador, mais gravoso e que causa deficiência direta na visão. É mais comum em ambientes externos, mas também pode acontecer devido a iluminações pontuais, fontes brilhantes intensas (luminárias, espelhos, materiais muito refletentes, janelas em espaços pouco iluminados)

É importante prever no projeto possíveis causas e pontos de ofuscamento, para prevenir os usuários de erros, fadigas e acidentes.

Para determinar a iluminância adequada pode-se utilizar os parâmetros da NBR 5413 (ABNT,1992). Definindo a idade do perfil trabalhado, o idoso acima de 60 anos, encontra-se a recomendação que a refletância do fundo da tarefa deve ser inferior a $30 \%$.

Para ambientes comerciais voltados ao atendimento do público da terceira idade, pode-se encaixá-los na classe $B$ de tarefas visuais, de acordo com a norma. A classe B é relativa, também, aos tipos de atividades que envolvam tarefas com requisitos visuais normais, escritórios, etc. E para estas condições, a norma recomenda uma iluminância entre 500 e 1000 lux.

Escolheu-se, abaixo, alguns ambientes listados na NBR 5413 (ABNT,1992) a fim de demonstrar quais são as recomendações de quantidade de lux para cada

NBR 5413

/1992

Itens

$3.1 ; 3.2 ; 4.1$

NBR ISO/CIE $8995-1 / 2013$

Item 4.4

NBR 5413

$/ 1992$

Itens

5.2.; 5.1 


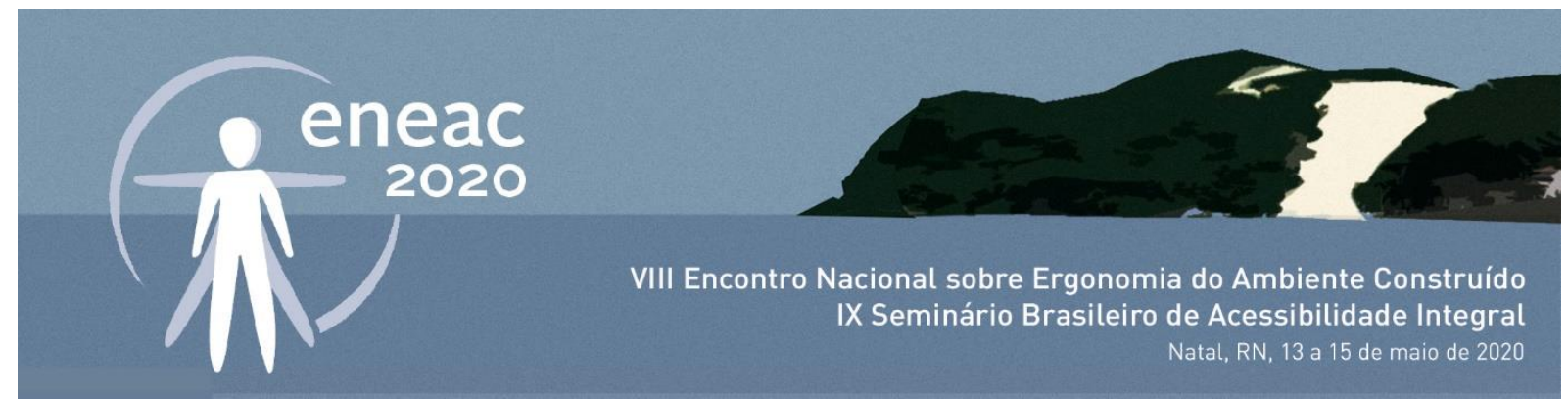

tipo de atividade.

/1992

O valor mais, dentre as três opções, deve ser escolhido quando:

Itens

A capacidade visual do usuário está abaixo da média - caso de muitos idosos;

5.2.4.2;

A superfície se apresenta com índices de reflexão baixos;

5.3.29;

Contrastes muito baixos estão presentes na tarefa, dificultando a 5.3.66;

diferenciação dos objetos manipulados;

O trabalho visual é crítico;

É de maior importância a exatidão da tarefa, por exemplo a manipulação de objetos pequenos como joias, aviamentos etc.

Em contrapartida, valores mais baixos podem ser escolhidos quando:

Os detalhes (objetos, dispositivos etc.) são de um tamanho excepcionalmente grande ou possuem alto contraste;

A tarefa é realizada rapidamente.

Ambientes:

Restaurantes: 100 - 150 - 200

Lanchonetes: 150 - 200 - 300

Autosserviço: 150 - 200 - 300

Portaria e recepção: 150 - 200 - 300

Indústria de artigos de ourivesaria e joalheria

Geral: 750 - 1000 - 1500

Local: $1500-2000-3000$

Lavatórios

Geral: 100 - 150 - 200

Espelho: 200 - $300-500$

Lojas

Vitrinas e balcões (centros comerciais de grandes cidades):

Geral: 750 - $1000-1500$

Iluminação suplementar com facho concentrado:

$-5000-7500$

Vitrinas e balcões (outros locais fora dos centros comerciais):

Geral: 300 - 500 - 750

Iluminação suplementar com facho concentrado:

\subsubsection{6;}

\section{3 .58}

NBR ISO/CIE $8995-1 / 2013$

Item 4.3.1 

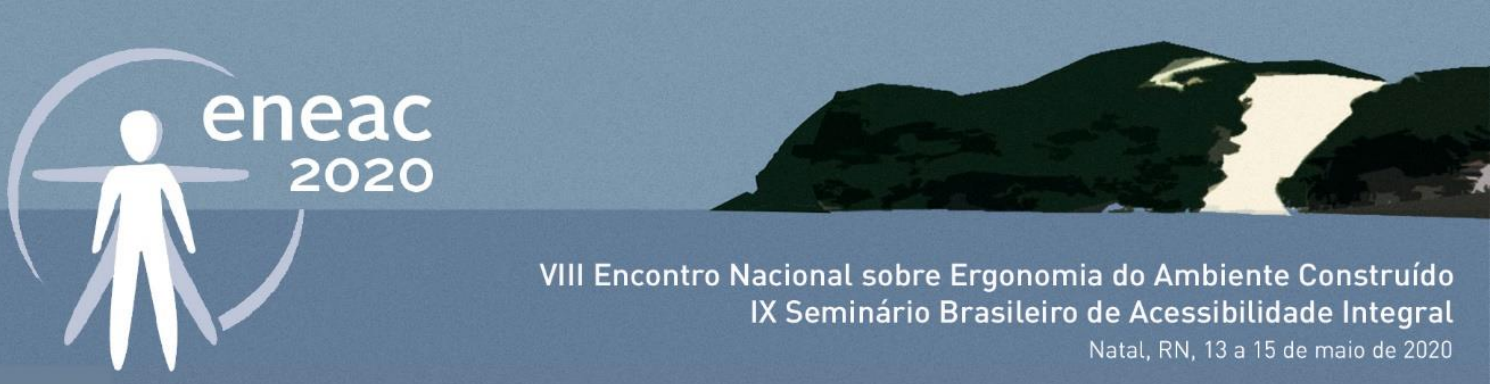

VIII Encontro Nacional sobre Ergonomia do Ambiente Construído IX Seminário Brasileiro de Acessibilidade Integral Natal, RN, 13 a 15 de maio de 2020

$1000-1500-2000$

Interior de:

Loja de artigos diversos: 300 - 500 - 750

Centros comerciais: 300 - 500 - 750

Outros locais: $300-300-750$

\section{F. Acessibilidade}

Deve-se, de acordo com a NBR 9050 (ABNT, 2015), prever:

No mínimo $90 \mathrm{~cm}$ de espaçamento livre para circulação, facultando o deslocamento de todos, inclusive pessoas em cadeiras de rodas;

Áreas para manobra de cadeira de rodas (sem deslocamento), por exemplo:

NBR 9050

$/ 2015$

Itens 4.3.1;

4.3.4; 4.3 .7

rotação de 900 - área de $1,20 \times 1,20 \mathrm{~m}$, rotação de 180 - $1,50 \times 1,20$, rotação 360 - $1,50 \times 1,50 \mathrm{~m}$;

Proteção contra queda ao longo de rotas/trajetórias, a fim de impedir que os usuários sofram ferimentos causados por quedas.

As maçanetas, barras antipânico, puxadores entre outros elementos de abertura de portas devem ter formato de fácil pega e não exigir precisão, força ou torção do pulso para manipulá-los.

O projeto deve conter sinalizações com informações necessárias aos usuários, seguindo os preceitos da NBR 9050 (ABNT), sendo alguns:

As informações devem ser transmitidas com o uso, no mínimo, de dois sentidos - visual e tátil ou visual e sonoro;

A sinalização deve ser autoexplicativa e legível para todos, incluindo pessoas com deficiência. Estas informações devem, preferencialmente, conter textos associados a símbolos.

Os sinais são classificados como: sinais de localização, advertência ou de instrução, e são usados individualmente ou combinados.

Os sinais de localização são aqueles que informam sobre o posicionamento de um determinado elemento no espaço. Os de advertência têm intuito de alertar previamente uma instrução. Sinais de instrução mostram uma ação de forma positiva e afirmativa, caso situados em rotas de fuga ou situações de risco, devem ser de forma continua e não intermitente.

Em relação às categorias os sinais podem ser de caráter: informativo, direcional e de emergência.

A sinalização informativa serve para identificar os ambientes e elementos neles contidos. A direcional indica a trajetória de um percurso e seus
NBR

/2015

Item 4.6.6

NBR

9050

/2015

Itens

5.1.3;

5.2.1;

NBR

9050/2015

Item 5.2.2;

NBR

9050

/2015

Item 5.2.4 
elementos associando setas indicativas a textos, figuras ou símbolos na sua forma visual. Guia de balizamento e piso tátil, na sua forma tátil, ou áudios de explanação de direcionamentos e segurança, como alarmes, na forma auditiva. Os sinais de emergê ncia são aqueles que mostram as rotas de fuga e saídas de emergência, quando há perigo.

A localização e disposição das sinalizações devem ser dispostas para ajudar o idoso a identificar facilmente as utilidades do local. Seguindo algumas recomendações:

Serem instaladas preferencialmente onde os usuários tomam suas decisões, numa sequência lógica de orientação;

Reiteradas sempre nas possibilidades de alterações de percurso;

Estarem dispostas em locais acessíveis para pessoas com deficiência;

Serem compreendidas por todos os usuários;

Serem posicionadas numa altura que favoreça a legibilidade e clareza da informação, tendo para pessoas em pé, como sentadas;

Serem instaladas em corrimões de escadas e rampas, indicando o pavimento em relevo e em Braille.

A diagramação das sinalizações deve seguir alguns requisitos:

Ser objetiva;

Ser em alto relevo e em Braille, quando tátil;

Estar na forma ativa e não passiva;

Enfatizar a sequência das ações;

Ser sempre na forma afirmativa e não negativa.

Devem possuir contraste, para melhor compreensão das informações pelos idosos, seja a nível visual, tátil e/ou auditivo.

No projeto voltado para idosos, deve-se utilizar o SIA - Símbolo internacional de acesso - para identificar a acessibilidade nos ambientes, mobiliário e equipamentos dispostos. Sua aplicação está inserida, principalmente em ambientes como: entradas, áreas e vagas de estacionamento de veículos, áreas de embarque e desembarque de pessoas com deficiência, sanitários, áreas de resgate, refugio e saídas de emergência, área reservada a pessoas em cadeira de rodas, equipamentos preferenciais para p.c.d ${ }^{1}$.

${ }^{1}$ Pessoas com deficiência.

Em virtude do perfil trabalhado, o idoso, a fim de agregar mais conforto na experiência de compra, é preferível utilizar rampas ${ }^{1}$ a escadas, quando necessário. Porém se não for viável a instalação de rampas ou elevadores, os degraus das escadas devem ser, quanto a sinalização visual:

NBR

9050

/2015

Itens 5.2.8.1;

5.2.8.2; 5.4.3

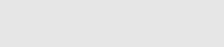
年 


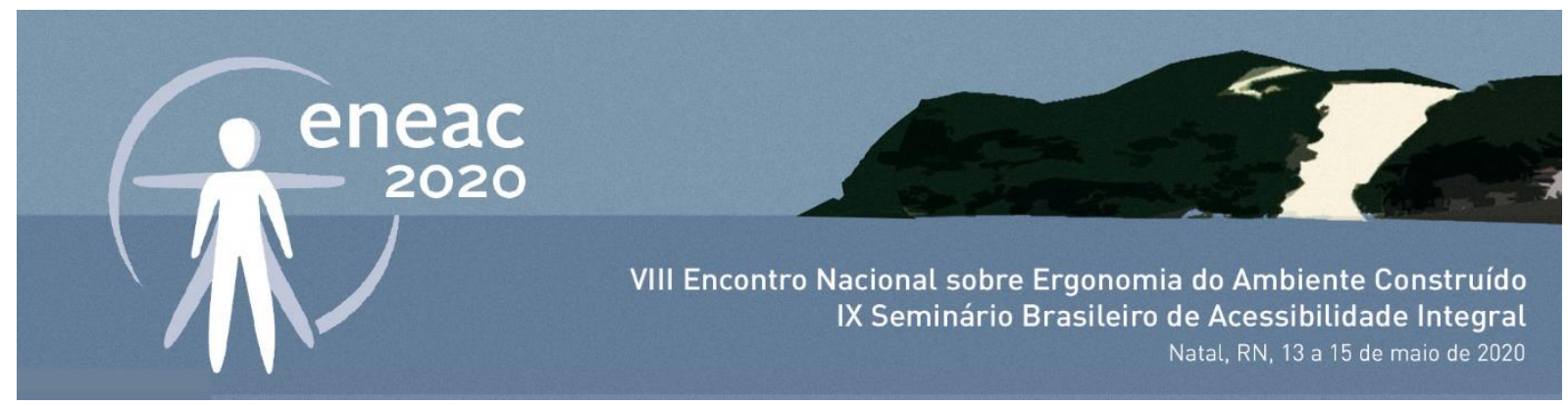

Aplicada nos pisos e espelhos em suas bordas laterais e/ou nas projeções dos corrimãos, de maneira a contrastar com o restante do piso e ser fotoluminescente ou retroiluminado;

Quanto a sinalização de elevadores e plataformas elevatórias, devem conte em relevo e em Braille:

Informações de sua operação nos painéis de chamadas;

O número do pavimento localizado na parte externa.

A sinalização tátil e visual de alerta no piso, deve existir sempre para:

Informar à pessoa com deficiência visual sobre a existência de desníveis ou situações de risco permanente;

Orientar o posicionamento adequado da pessoa com deficiência visual para o uso de elevadores, equipamentos de autoatendimento ou serviços;

Informar os usuários sobre as mudanças de direção ou opções de percursos, o início e o término de degraus, escadas e rampas e a existência de patamares nas escadas e rampas.

A sinalização tátil e visual direcional no piso, deve estar presente no sentido da trajetória dos usuários, quando não houver linha-guia identificável, tanto em ambientes externos, quando internos.

Já a sinalização de emergência deve indicar ao público as saídas de emergência e rotas de fuga, através de sinais para a saída. Elas sempre devem utilizar os três sentidos: visual, tátil e auditivo. Os alarmes são dispositivos com a finalidade de alertar situações de emergência e, obrigatoriamente, devem ser aplicados nos ambientes confinados, como boxes, cabines, sanitários acessíveis e vestiários isolados - por exemplo em provadores de lojas de roupas, academias e outros ambientes voltados a atender também o público idoso. Outra aplicação essencial é na saída de garagem em passeio público.

1 São consideradas rampas as superfícies de piso com declividade igual ou superior a $5 \%$.

Os corrimãos e guarda-corpos são equipamentos essenciais para a segurança do idoso e para fornecê-los maior autonomia na experiência cotidiana. Os corrimãos podem se encontrar acoplados, ou não, aos guarda-corpo, porém sempre devem ser de materiais rígidos e firmemente fixados a paredes e a barras de suporte.

Nas escadas e rampas, devem ser instalados em duas alturas, $92 \mathrm{~cm}$ e $70 \mathrm{~cm}$ do chão, em ambos os lados. Se forem degraus isolados', necessita-se apenas de uma barra de apoio horizontal ou vertical, com no mínimo $30 \mathrm{~cm}$ de comprimento e a $75 \mathrm{~cm}$ do chão.

Outras recomendações: 


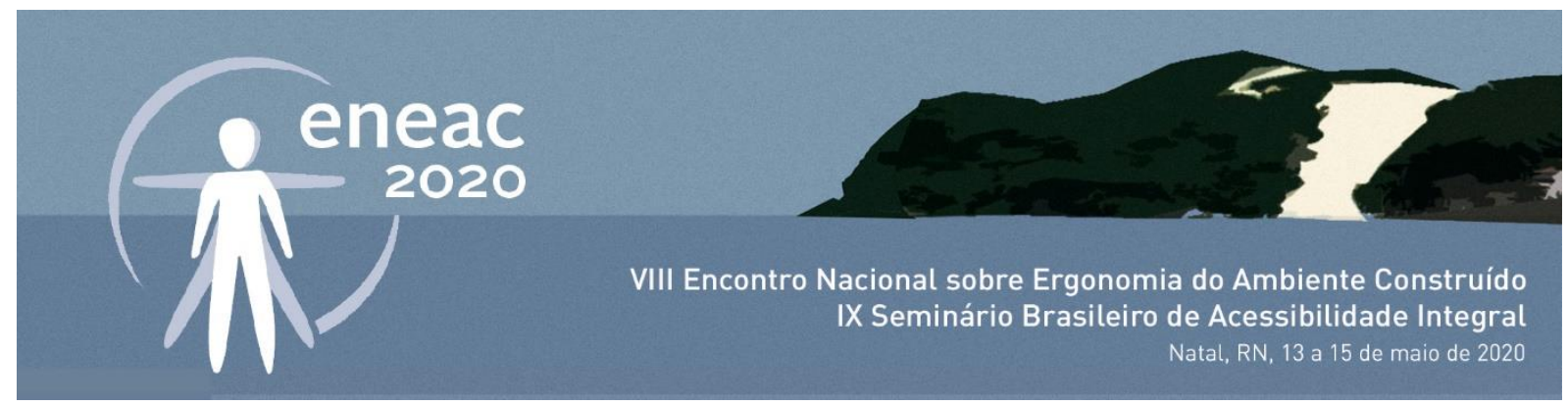

Os corrimãos laterais não devem conter interrupções nos patamares e ter prolongamento de, no mínimo, $30 \mathrm{~cm}$ após o termino da escada/rampa de forma a não prejudicar a circulação adjacente;

O acabamento deve ser recurvado, sem protuberâncias.

${ }^{1}$ Degrau isolado é a sequência de até dois degraus.

\section{CONCLUSÃO}

Conclui-se com este estudo a importância de se conhecer previamente as necessidades e peculiaridades do público da terceira idade ao se projetar ambientes voltados a atendê-los. É relevante entender como as doenças e outras limitações próprias da idade mais avançada podem impactar na interação do homem com o meio, como por exemplo, menores alcances manuais, acuidade visual reduzida e maior tempo para as tomadas de decisões. Por fim, o intuito maior deste trabalho foi o de elucidar alguns aspectos imprescindíveis no tocante a este público, de forma que, ao contemplá-los, o resultado possa ser um ambiente que fornecerá melhor interação do idoso com o meio, respeitando sua natureza e proporcionando-o maior autonomia. Além de fazer o elo entre as particularidades da condição fisiológica do público idoso com as normas técnicas voltadas para o ambiente interno e ao público geral, tem-se o intuito de mostrar aos projetistas de forma clara alguns dos elementos e aspectos que devem ser pensados e projetados para oferecer autonomia e bemestar aos idosos, de forma a integrar no projeto de interiores, não só o bem-estar das outras faixas etárias comumente consideradas, mas também de um público por vezes negligenciado, o idoso.

Por fim, esta cartilha busca aprimorar o ato de projetar em dois eixos: primeiro em alertar sobre a necessidade de projetar ambientes comerciais sempre aptos para atender o público idoso, o qual está cada vez mais presente e ativo no comércio em geral e, segundo, facilitar de tal modo o pensar no ambiente interno para os idosos, que o torne descomplicado e habitual para os profissionais da área.

\section{REFERÊNCIAS}

IBGE. Instituto Brasileiro de Geografia e Estatística, 2010. Disponível em:

http://www.ibge.gov.br/cidadesat/topwindow.htm?1 Acesso: 01 jan 2019.

CHAIMOWICZ, Flávio. Saúde do idoso. Editora Coopmed, Belo Horizonte, 2009, 174 p.

COOK, A. M.; POLGAR, J. M.; HUSSEY, S. M. Cook \& Hussey's assistive technologies: principles and practice. 3. ed. St Louis: Mosby Elsevier, 2008.

GRUBER, Crislaine et al. O vestir na vida dos idosos: contribuições da ergonomia e das tecnologias assistivas. Revista Educação. Moda Palavra E-periódico, Santa Catarina, n. 9, p. 151-178, jan. 2017

BRASIL. Lei no 10.741, de 01 de outubro de 2003. Estatuto do Idoso

BRASIL. Lei n. 13.146, de 06 de julho de 2015. Lei Brasileira de Inclusão da Pessoa com Deficiência.

BRASIL. Envelhecimento Ativo: Uma Política de Saúde / World Health Organization. 1. Ed. Brasília: Organização PanAmericana da Saúde, 2005. 62p 


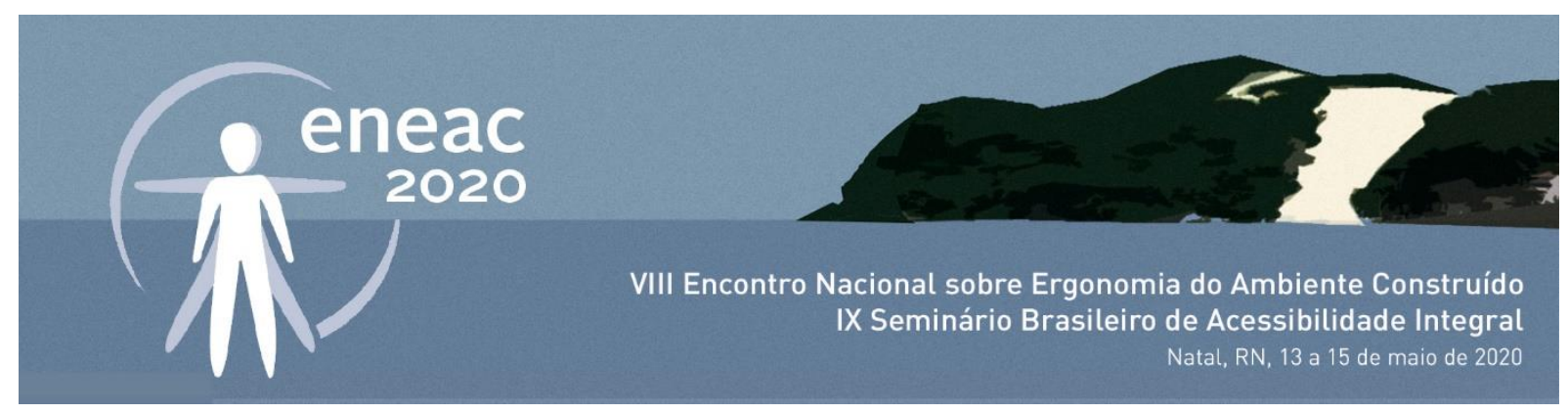

FALZON, Pierre. Ergonomia. 2. ed. Ed. Blucher, São Paulo: 2018

FERNANDES, JÚLIO CÉSAR FELIX DE ALENCAR. ABORDAGEM DA ERGONOMIA PARA A ANÁLISE DA ACESSIBILIDADE DE UMA INSTITUIÇÃO DE LONGA PERMANÊNCIA PARA IDOSOS DA CIDADE DE NATAL-RN. 2012. $213 p$.

LAVILLE, A.; VOLKOFF S. Envelhecimento e Trabalho. In: Ergonomia. FALZON, Pierre. Ed. Blucher, São Paulo: 2007 ASSOCIAÇÃO BRASILEIRA DE NORMAS TÉCNICAS. NBR 5413: Iluminância de interiores. Rio de Janeiro, 1992. 13 p. ASSOCIAÇÃO BRASILEIRA DE NORMAS TÉCNICAS. NBR 9050: Acessibilidade a edificações, mobiliário, espaços e equipamentos urbanos. $3 \mathrm{ed}$. Rio de Janeiro, 2015. 148 p.

ASSOCIAÇÃO BRASILEIRA DE NORMAS TÉCNICAS. NBR ISO/CIE 8995-1: lluminação de ambientes de trabalho. 1 ed. Rio de Janeiro, 2013. $46 p$

BRASIL. Ministério do Trabalho e Emprego. NR 17- Ergonomia. Brasilia: Ministério do Trabalho e Emprego, 2009. 